\title{
Histological and Immunohistochemical Study on the Toxic Effects of Anthracene on the lung and liver of Adult Male Albino Rats and the Possible Protective Role of Ocimum gratissimum Extract
}

\author{
Issa NM and El-Sherif $\mathrm{NM}^{*}$
}

Department of Anatomy and Embryology, Faculty of Medicine, Menoufiya University, Egypt

*Corresponding author: El-Sherif NM, Department of Anatomy and Embryology, Faculty of Medicine, Menoufiya University, Egypt, E-mail: neveensherif@yahoo.com

Citation: Issa NM, El-Sherif NM (2015) Histological and Immunohistochemical Study on the Toxic Effects of Anthracene on the lung and liver of Adult Male Albino Rats and the Possible Protective Role of Ocimum gratissimum Extract. J Cell Biol Histol 1(1): 103. doi: 10.15744/2638-082X.1.103

Received Date: August 01, 2015 Accepted Date: September 04, 2015 Published Date: September 09, 2015

\begin{abstract}
Anthracene is the simplest tricyclic aromatic hydrocarbon. It has been identified in surface and drinking water, ambient air; exhaust emissions, smoke of cigarettes and cigars and in smoked foods and edible aquatic organisms. It is primarily used as an intermediate in the production of dyes. The aim of this study was to demonstrate the toxic effects of anthracene on the lung and liver of adult male albino rats and evaluate the possible protective role of basil (Ocimum gratissimum). Our results showed that anthracene induced disrupted lung architecture with collapsed alveoli, inflammatory cellular infiltration, congested thickened pulmonary vessels and extravasated red blood cells. There was a significant increase in the percentage area of positive inducible nitric oxide synthase (iNOS) immunoreaction and in the count of alveolar macrophages, compared with the control group. Anthracene induced histological changes in the liver, including proliferation of bile ducts and mononuclear cellular infiltration at the portal tracts. Some hepatocytes appeared swollen with vacuolated cytoplasm, whereas others showed disintegrated nuclei (karyorrhexis). This was confirmed by a significant increase in the mean \% area of immunostaining for glial fibrillary acidic protein (GFAP) and caspase-3. Co-administration of Ocimum gratissimum and anthracene preserved a near-normal lung and liver structure.
\end{abstract}

Keywords: Anthracene; Lung; Liver; Immunohistochemistry; Ocimum gratissimum

\section{Introduction}

Anthracene is one of a group of chemicals called polycyclic aromatic hydrocarbons (PAHs). Anthracene can vary in appearance from a colorless to pale yellow crystals, consisting of three fused benzene rings [1]. PAHs were among the first discovered environmental pollutants and carcinogens. PAHs are widely found in the air, food and drinking water [2]. Inhalation of particleborne or gaseous PAHs occurs through tobacco smoke, automobile exhausts, and combustion processes, which include burning of coal, oil, and biomass [3]. Industries where exposure to PAHs is likely to occur include coke ovens and coal tar use, iron and steel works, aluminum works, foundries, carbon electrode and carbon black manufacture, asphalt manufacture and use, and many others. In these industries inhalation of volatile compounds or of particles with adsorbed PAHs and dermal absorption of mixtures containing PAHs may be important routes of exposure [4]. The non-occupational exposure to PAHs for a non-smoking person can be associated with diet, mainly through cereals, vegetables and cooked food especially that prepared on open flame as barbecued meat [5]. Ocimum gratissimum is a herbaceous plant that belongs to the Lamiaceae family commonly known as wild, sweet basil, or clove basil [6]. O. gratissimum has been used extensively in the traditional style of medicine in many countries, as well as for medicinal, condiment, and culinary purposes. Decoctions of the leaves are used to treat mental illness, convulsions, fungal infections, catarrh and fever, barrenness, as a diaphoretic and an antipyretic, and for its anti-inflammatory activity [7]. O. gratissimum is an antioxidant with volatile oils that contain phenolic eugenols, saponins, flavonoids, phenylpropanoids, linalool, and alkaloids as pharmacologically active agents. These active agents confer on it antioxidative, chemotherapeutic, antispasmodic, and analgesic actions [8]. O. gratissimum leaves have hypolipidemic activity as they decrease the serum lipid profile. Moreover, flavonoids and alkaloids found in O. gratissimum have a better effect in combating the adverse effects of hypercholesterolemia on the testes of male rats [9]. To the best of our knowledge, very few studies have been performed to demonstrate the pulmonary and hepatic injury associated with anthracene exposure. So, the aim of this study was to demonstrate the effect of anthracene on the lung and liver of adult male albino rats and evaluate the possible protective role of basil. 


\section{Methodology}

\section{Animals}

Twenty adult wistar male albino rat weighting 150-200 grams were used in this experiment. Food and water were provided ad libitum for 5 days before use in the Anatomy Department, Faculty of medicine, Menoufiya University. All aspects of animal care and treatment were carried out according to the local guidelines of the ethical committee for animal research.

\section{Chemicals}

(1) Anthracene (molecular weight $178.22 \mathrm{~g} / \mathrm{mol}$ ) was obtained as a powder from Adwic Co., Cairo, Egypt.

(2) Basil leaves were purchased from the Chemistry Department, Agricultural Research Center, Cairo, Egypt.

\section{Experimental protocol}

Group I: (control) included 10 rats and was further divided into 2 equal subgroups:

- Subgroup Ia was kept without any treatment throughout the experimental period

- Subgroup Ib received oral treatment of O. gratissimum $(300 \mathrm{mg} / \mathrm{kg} /$ day) by gastric tube [6].

Group II: (anthracene-treated) included 5 rats that were injected intraperitoneally with anthracene at a dose of $50 \mathrm{mg} / \mathrm{kg}$ [2].

Group III: (protected) included 5 rats that received O. gratissimum extract (300 $\mathrm{mg} / \mathrm{kg} /$ day) followed 60 min later by anthracene $(50 \mathrm{mg} / \mathrm{kg})$.

\section{Histological study}

Lung and liver samples were fixed in $10 \%$ formol saline and processed to prepare $5 \mu \mathrm{m}$-thick paraffin sections for

\section{Haematoxylin and Eosin (H\&E) stain}

Immunohistochemical stains for lung sections: For alveolar macrophages (CD68) and iNOS immunohistochemistry using the avidin-biotin-peroxidase method was used. Paraffin sections of 5 - $\mu \mathrm{m}$ thickness were dewaxed in xylene, rehydrated in descending series of ethanol, and immersed in $0.3 \% \mathrm{H}_{2} \mathrm{O}_{2}$ for 30 min to block endogenous peroxidase. Antigens were retrieved by microwaving for 15 min in citrate buffer ( $\mathrm{pH}$ 6.0). Nonspecific binding was blocked with 10\% goat serum (Dako Ltd, Cambridgeshire, UK) for 30 min. Sections were incubated overnight at $4{ }^{\circ} \mathrm{C}$ with iNOS antibody (rabbit polyclonal antibody, catalog no. 611473; Transduction Laboratories, San Diego, California, USA; at a dilution of 1:200) and CD68 antibody (mouse monoclonal antibody, code NCLL-CD68; Leica Biosystems, Benton La, Newcastle Ltd, UK; at a dilution of 1:100). The sections were incubated with biotinylated antirabbit or antimouse immunoglobulins (Dako Ltd) for the corresponding primary antibody. Sections were incubated with the avidin-biotin-horseradish peroxidase complex according to the manufacturer's instructions. Peroxides were visualized by incubating the sections in diaminobenzidine (Sigma Chemical Co., Poole, UK) and $\mathrm{H}_{2} \mathrm{O}_{2}$. Negative control lung sections were processed in the above mentioned sequence but omitting the incubation with the primary antibody.

Immunohistochemical stains for liver sections: By using the avidin-biotin-peroxidase method, all specimens were processed routinely. Monoclonal mouse anti-GFAP (dilution 1:100) and the polyclonal rabbit anticleaved caspase-3 (diluted 1:50) (Novus Biologicals, Littleton, Colorado, USA) were used. To ensure antibody specificity, negative control samples were processed under the same conditions but without using the primary antibody. Brown color in the cytoplasm was considered a positive reaction. The $\%$ area of positive cells was measured by means of image analysis in five randomly selected, separate, $\times 400$ magnified fields from each slide. All images were semi quantitatively analyzed using Image-Pro Plus (version 6.0; Media Cybernetics; Silver Spring, Maryland, USA).

\section{Statistical analysis}

Data were analyzed using Graph-Pad prism, San Diego California USA (version 4). All values were expressed as mean \pm SEM. Differences among the groups were compared by analysis of variance test followed by Bonferroni's multiple comparison tests. p-values less than 0.05 were considered significant.

\section{Preparation of $O$. gratissimum extracts}

Fresh leaves of $O$. gratissimum were washed, shade dried and finely powdered for extraction. The aqueous polyphenols were extracted in distilled water. $5 \mathrm{~g}$ of leaf powder was mixed with $100 \mathrm{~mL}$ of double distilled water and the mixture was allowed to stand overnight for maximum extraction of polyphenols. Percolation of the extract was performed at room temperature in two stages. Collected filtrate was evaporated below $5^{\circ} \mathrm{C}$ to obtain the final product in the form of residues which were stored under refrigerated conditions [8]. Anthracene was injected intraperitoneally $50 \mathrm{mg} / \mathrm{kg}$ for three months [2].

\section{Results}

There was no significant difference between subgroups Ia and Ib rats in all the outcomes at each time point used in the study; therefore, these two subgroups were pooled in one group (control). 


\section{Lung sections}

H\&E stain: Examination of lung sections of group I (control) showed normal lung architecture with polygonal alveoli, alveolar sacs, a bronchiole, and blood vessels. The alveoli appeared inflated with thin interalveolar septa (Figure 1a and 1c). In group II (anthracene-treated), the most prominent finding was the massive cellular infiltration with lipid droplets in between Dilated, congested blood vessels were also noticed. Other fields revealed bronchioles partially obstructed by shed epithelial cells and surrounded by cellular infiltration. Thick interalveolar septa exhibited narrow alveolar spaces. Congested blood vessels appeared with markedly thickened wall. Obvious thickening of the interalveolar septa were detected. Cellular infiltration was observed in the thickened septa and around blood vessels. Other areas of the lung revealed massive cellular infiltration partially compressing occasional bronchioles. Some fields revealed intense extravasation of red blood cells (RBCs) in most of the alveoli to the extent that many of them appeared obliterated. Intra-alveolar exudate was also detected in many alveoli. In contrast, compensatory dilatation was seen in some alveoli and alveolar sacs (Figure 1d and 1i). Group III (extract-treated) sections preserved nearly normal lung structure with inflated alveoli and relatively thin interalveolar septa. However, some amount of inflammatory cell infiltration and a few congested blood vessels were still present (Figure $1 \mathrm{j}$ and 11 ).

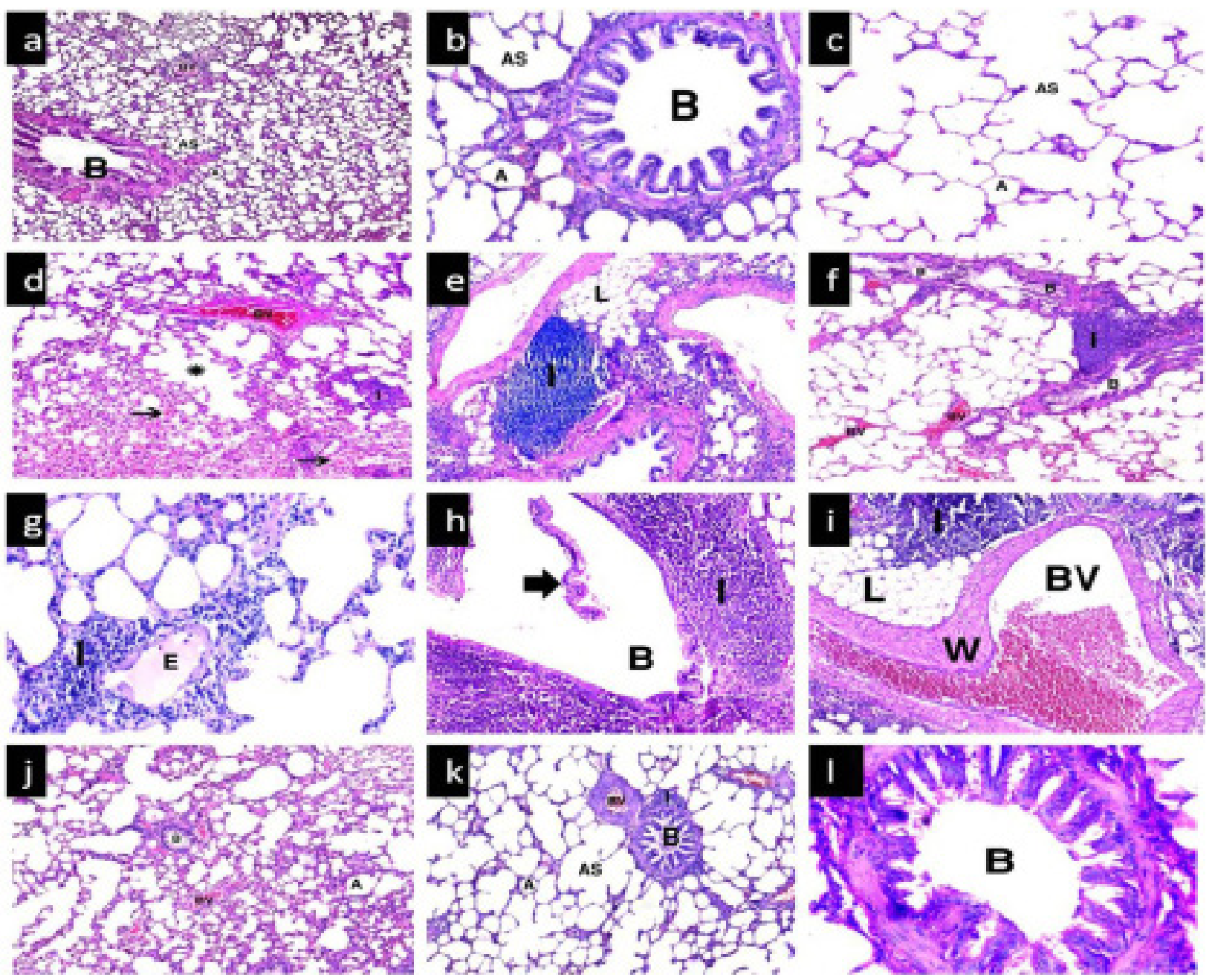

Figure 1: (a-c) group I showing normal lung architecture with polygonal alveoli (A) having thin interalveolar septa, alveolar sacs (AS), a bronchiole (B) and blood vessels (BV); (d-i) group II showing diffuse mononuclear cellular infiltration (I) with lipid droplets (L) inbetween in some areas. Dilated congested blood vessels (BV) with markedly thickened wall (W) were noticed. Many extravasated red blood cells in the lumen of alveoli (thin arrow) are observed. Some alveoli show pale acidophilic intra-alveolar exudate (E), others show compensatory dilatation $\left({ }^{*}\right)$. Some bronchioles appear compressed by massive peri-bronchiolar infiltration while others show sloughed epithelium (thick arrow); (j-i) group III shows restoration of normal lung architecture with some areas of congested blood vessels (BV) and peri-bronchiolar infiltration (I).H\&E (a,d,g,j) $\mathbf{x 1 0 0 ; ~ ( b , e , h , k ) ~} \mathbf{x}$ $200 ;(c, f, i, l) \times 400$

Quantitative immunohistochemical assessment and statistical analysis (Figure 2; Graphs 1 and 2): A significant increase in the number of alveolar macrophages (CD68 cells) in the Anthracene-treated group compared with controls (7.54 \pm 2.29 vs $2.52 \pm 1.82$ ), which was significantly reduced in the protected group (3.18 \pm 2.56$)$. The elevated expression of CD68 was associated with a significant up-regulation of iNOS expression, a marker of oxidative stress in group II compared with control group (8.09 \pm 1.28 vs $2.98 \pm 1.6)$. In the protected group, iNOS expression was significantly down-regulated compared with Anthracene-treated rats (4.27士3.34). 


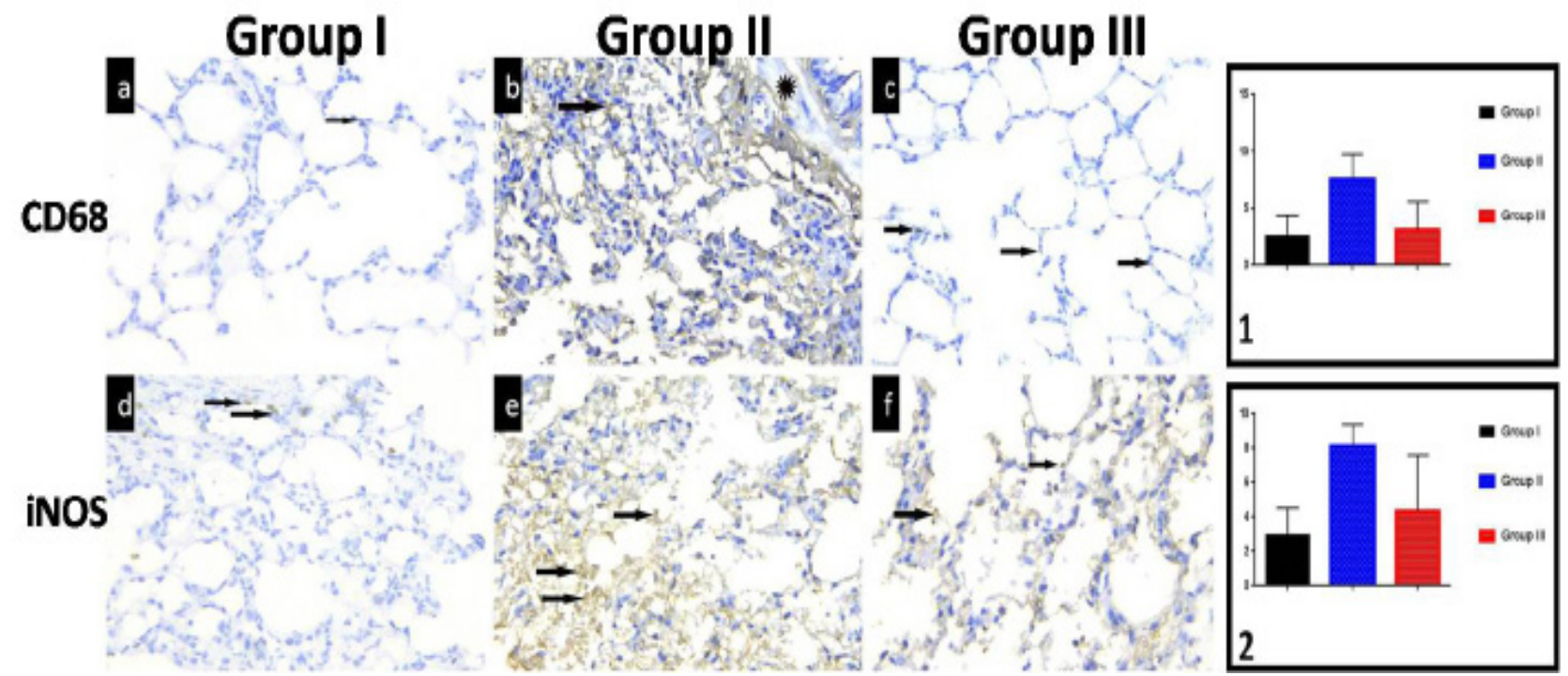

Figure 2: (a) A normal number of alveolar macrophages appear as few brown positively stained cells in the interalveolar septa (arrow) in lung sections of group I; (b) Group II show many brown positively stained cells in the interalveolar septa (arrow) and in the wall of the bronchioles $\left(^{*}\right)$; (c) Sections of group III show decreased number of positively stained cells (arrow) near to normal. CD68, x 400; (d) Normal distribution of brown positive immunoreactions for iNOS (arrow) in lung sections of group I; (e) Group II sections show marked increase in brown positive immunoreactions (arrow) compared with the control group; (f) More or less normal brown positive immunoreactions (arrow) could be detected in sections of group III. iNOS, $\mathbf{x}$ 400. Graphs 1 and 2: Area \% of CD68, iNOS

\section{Liver sections}

H\&E stain: In the control group, sections showed the normal architecture of the classic hepatic lobules, with plates of polygonal hepatocytes radiating from the central veins and separated by blood sinusoids. The hepatocytes revealed an acidophilic granular finely vacuolated cytoplasm and rounded vesicular nuclei. The portal tract containing branches of portal vein, hepatic artery, and bile duct was observed (Figure 3a and 3c). The Anthracene-treated group revealed loss of normal hepatic architecture (hepatocyte boundaries not be distinguishable) with dilatation and congestion of the central veins. Some hepatocytes showed cytoplasmic vacuolation with disintegrated nuclei (karyorrhexis). In the majority of sections the nuclei appeared deeply stained. There was proliferation of bile ducts that had irregular outlines and congested dilated portal vessels (Figure 3d and 3f). The Protected group showed a nearly normal liver architecture with blood sinusoids, and portal tracts with some inflammatory cellular infiltration. Some central veins showed mild congestion and some hepatocytes still showed dark disintegrated nuclei (Figure $3 \mathrm{~g}$ and $3 \mathrm{i}$ ).
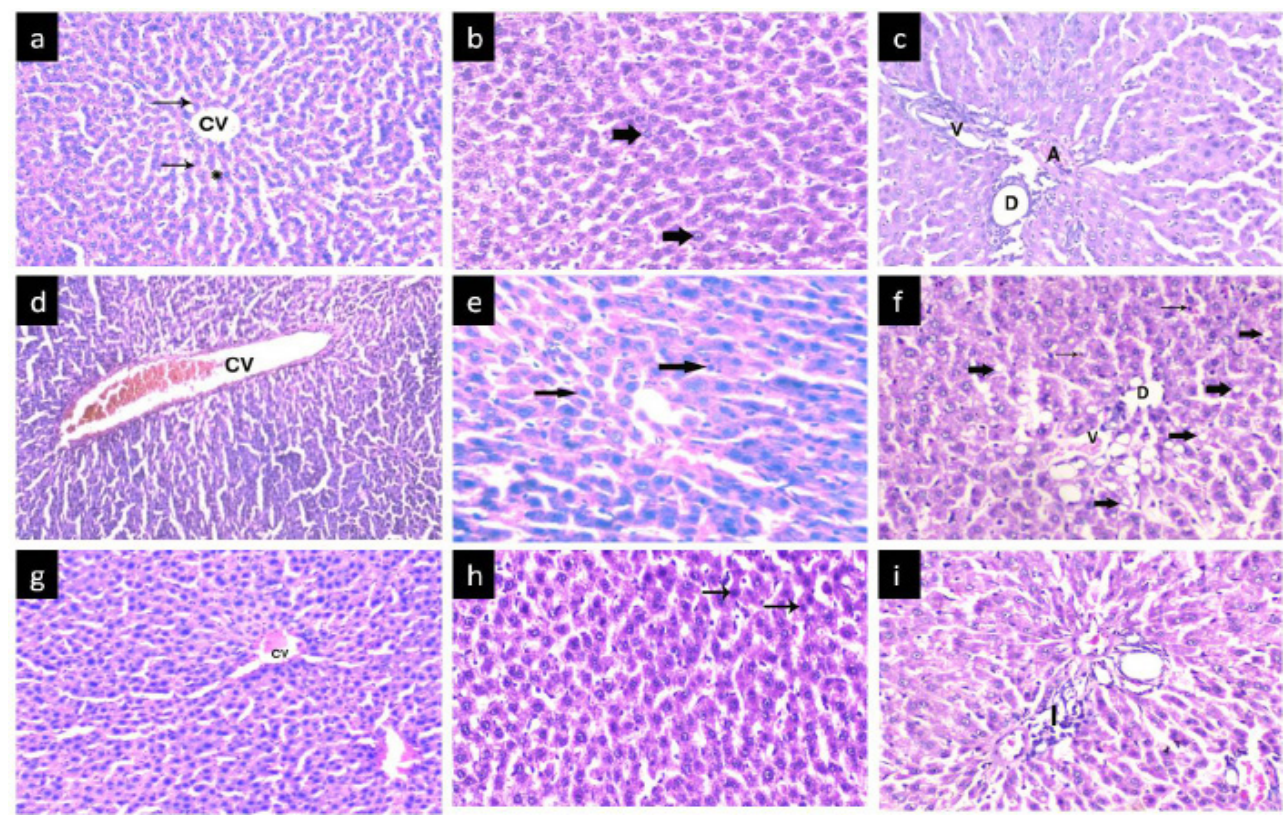

Figure 3: (a-c) group I showing classical hepatic lobule containing central vein (CV) surrounded by radiating hepatic cords (thin arrow) formed from hepatocytes with vacuolar cytoplasm and large, rounded central vesicular nuclei (thick arrow) and separated from each other by hepatic sinusoids $\left(^{*}\right)$. Note the portal tract with branches of portal vein (v), hepatic artery (A), and bile duct (D); (d-f) group II shows loss of hepatic architecture with dilated congested central vein $(\mathrm{CV})$. Some hepatocytes showed cytoplasmic vacuolation (thick arrow) with disintegrated dark nuclei (thin arrow). Note the expanded portal tract with proliferation of bile ducts (D) and congested dilated portal vessel (v); (g-i) Protected group shows nearly normal portal tracts with some inflammatory cellular infiltration (I); Some central veins showed mild congestion (CV). Some hepatocytes still show dark disintegrated nuclei (thin arrow). $H \& E(a, d, g) \times ,200 ;(b, c, e, f, h, i) \times 400$ 
Quantitative immunohistochemical assessment and statistical analysis (Figure 4; Graphs 3 and 4): The expression of GFAPpositive cells was significantly increased in the Anthracene-treated group compared with the control (7.07 \pm 0.37 vs $2.87 \pm 2.52)$, but showed a significant decrease in the protected group (4.68 \pm 1.19$)$. Anthracene-treated rats showed a significant increase in caspase- 3 positive cells compared with control (19.13 \pm 0.91 vs $9.56 \pm 1.18$ ), but this increase was significantly decreased in protected livers (11.05 \pm 4.28$)$.

Group I

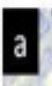

GFAP

Caspase-3

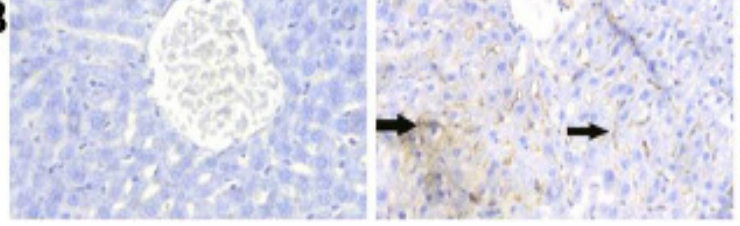

Group II
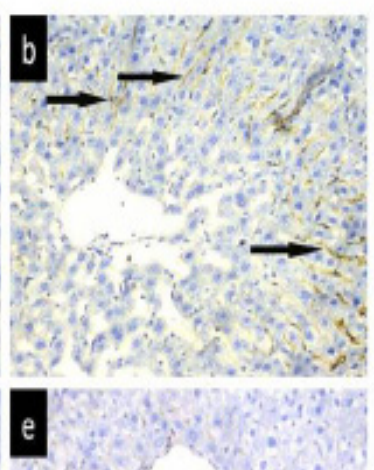

\section{d}
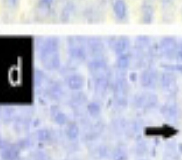
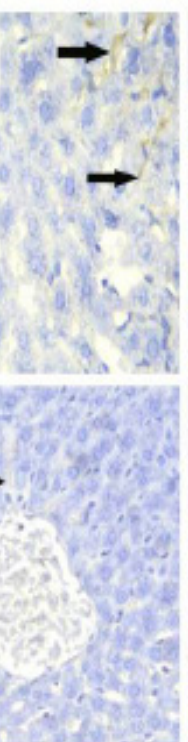

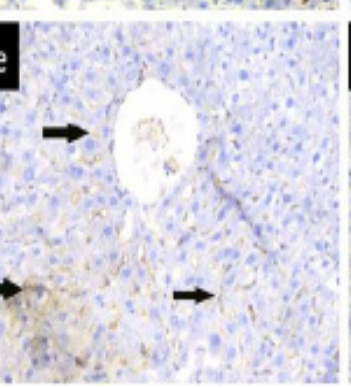

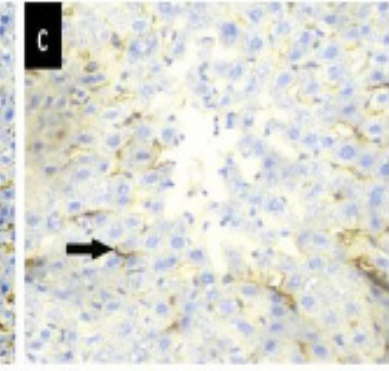

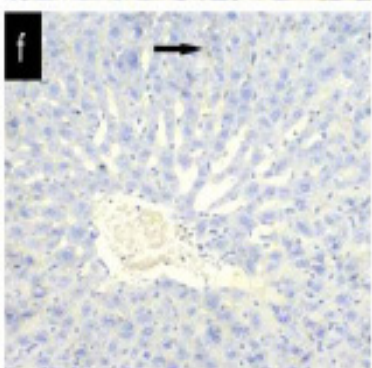

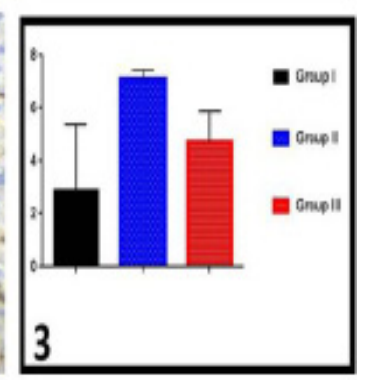

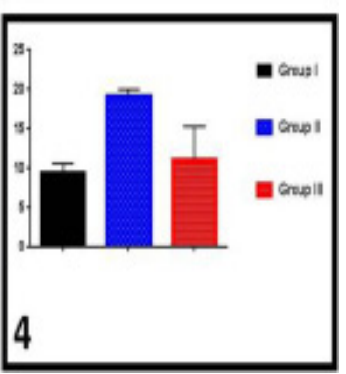

Figure 4: (a) In group I, GFAP-positive cells are distributed throughout the liver zones with no consistent differences between them. They are particularly identified in the pericentral region (arrow); (b) Group II shows an apparent increase in the number of GFAP positive cells, particularly around the central vein (arrow); (c) An apparent decrease in the number of GFAP-positive cells is observed around the central vein in group III (arrow); GFAP,x400; (d) Group I shows hepatocytes with minimal caspase-3 reaction (arrow); (e) Group II shows multiple apoptotic hepatocytes with increased immune reaction (arrow); (f) In group III, some apoptotic hepatocytes with positive reaction are noticed. Caspase-3,x400. Graphs 3,4: Area \% of GFAP, caspase- 3

\section{Discussion}

Anthracene appears to target the skin, blood, stomach, intestines and the lymph system. Exposure to high doses of anthracene for a short time can cause damage to the skin. It can cause burning, itching edema and a buildup of fluid in tissues. Humans exposed to anthracene experienced headaches, nausea, loss of appetite, inflammation or swelling of the stomach and intestines. In addition, their reaction time slowed and they felt weak [10]. In the current study, investigations were focused on the lung and liver to demonstrate the histological and immunohistochemical changes.

In lung sections, there was the massive cellular infiltration, lipid droplets and dilated congested blood vessels with markedly thickened wall. Other fields revealed bronchioles partially obstructed by shed epithelial cells and surrounded by cellular infiltration. Obvious thickening of the interalveolar septa were detected. Cellular infiltration was observed in the thickened septa and around blood vessels. Other areas of the lung revealed massive cellular infiltration partially compressing some bronchioles. Some fields revealed intense extravasation of red blood cells in most of the alveoli. Intra-alveolar exudate was also detected. Compensatory dilatation was seen in some alveoli and alveolar sacs. A significant increase in the number of alveolar macrophages (CD68) cells in the Anthracene treated group compared with controls was detected. The elevated expression of CD68 was associated with a significant up-regulation of iNOS expression, a marker of oxidative stress. Mononuclear cellular infiltration with significant increase in macrophage number was seen in the present study. In accordance, neutrophil accumulation in the lungs during the inflammatory process was reported and was found to be followed by reactive oxygen species production that exceeded the antioxidant capacity of the lungs. Consequently, lipid peroxidation led to tissue injury and cell death $[11,12]$. Likewise, pulmonary macrophages play a prominent role in the molecular pathogenesis of the sepsis-related lung inflammation [13]. Recent research reported marked population expansion and phenotypic changes of pulmonary macrophages due to recruitment of circulating monocytes into the alveolar and interstitial space [14]. These studies were supported by the findings of increased concentrations of circulating intrapulmonary macrophages and macrophage inhibitory factor (MIF) detected in the lungs of septic patients. Importantly, MIF was shown to potentiate the production of tumor necrosis factor- $\alpha$ (TNF- $\alpha$ ) and interleukin-8 (IL-8) [15]. Consistent with these studies, it has been documented that MIF potentiated the lethal effects of endotoxin in rodents [16]. It therefore appears that alveolar macrophages promote tissue destructive inflammatory processes. This could explain the inflammatory cellular infiltration, vascular congestion, extravasated RBCs. Dilated blood vessels seen in group II of this study might be due to a direct vasodilatation effect of anthracene, as stated by some authors [2], as anthracene increased endothelial nitric oxide synthase. Anthracene also enhanced thickening of the wall of the blood vessels. This could be attributed to oxidative stress and cyclophilin A. Cyclophilin A i- 
s a chaperone protein that is secreted from vascular smooth muscle cells in response to ROS and stimulates vascular smooth muscle cell proliferation, migration, and inflammatory cell recruitment in vitro and in vivo [4]. Fatty infiltration recorded in the present work was explained by Marmugi, et al. [17], who suggested that exposure to anthracene might influence de-novo fatty acid synthesis through increased expression of lipogenic genes. They added that anthracene contributed to hepatic steatosis in mice. This study showed thickening of interalveolar septa, which could be attributed to the increased interstitial collagen fiber deposition and marked cellular infiltration with lymphocytes, neutrophils, eosinophils, and macrophages [18]. Homogenous exudate was seen in the thickened interalveolar septa. This might be attributed to the increased alveolar-capillary barrier permeability that would allow for extravasation of protein-enriched fluid into the alveoli and septa. In turn, the presence of exudate in the alveoli, with the inactivation of lung surfactant and alveolar collapse, life-threatening hypoxemia, impaired $\mathrm{CO}_{2}$ elimination, and decreased lung compliance can result [19]. Inducible nitric oxide synthase (iNOS) stimulation leads to production of a large amount of harmful nitric oxide (NO). NO reacts with superoxide anion, which is produced as intermediary product of oxidative stress [20]. iNOS was first cloned and characterized in macrophages, but its activity has been detected in a variety of cell types. Hence, iNOS expression in immunohistochemical studies has been used as a marker of oxidative stress [21].

The liver is the main target of toxicity of several compounds. This is because $75 \%$ of blood coming into the liver arrives directly from the gastrointestinal organs and then from the spleen through portal veins, which bring drugs and xenobiotics in concentrated form [22]. The pathophysiological mechanisms of hepatotoxicity include both hepatocellular and extracellular mechanisms [23]. The anthracene-treated group revealed loss of normal hepatic architecture with dilatation and congestion of the central veins. Some hepatocytes showed cytoplasmic vacuolation with disintegrated nuclei. In the majority of sections, proliferation of bile ducts and congested dilated portal vessels was noticed. The expression of GFAP-positive cells was significantly increased in the anthracenetreated group. There was also a significant increase in caspase-3 positive cells compared with controls. Many theories were proposed to explain the mechanism by which anthracene could induce hepatotoxicity. One of these theories was induction of oxidative stress and lipid peroxidation. Malondialdehyde MDA is a major oxidation product of peroxidized polyunsaturated fatty acids, and increased MDA content is an important indicator of lipid peroxidation. It was also reported stated that the lipid peroxidation end product (MDA) was significantly increased in the erythrocyte, liver, brain, and muscle of rats treated with anthracene [24]. In the present work, hepatocytes showed cytoplasmic vacuolation. Similar results were described previously and were attributed to increased permeability of the cell membrane in response to cell injury leading to an increase in the volume of intracellular water as it sufficiently accumulates within the cell and produces cytoplasmic vacuolation [1]. It was suggested that injurious agents may also interfere with the ATP-dependent sodium-potassium pump by increasing the permeability of the cell membrane to sodium, thereby exceeding the capacity of the pump to extrude sodium, or damaging the pump directly. Consequently, accumulation of sodium in the cell leads to increase in water content and the cell will swell, a condition called hydropic degeneration [25]. In this work, proliferation of bile ducts at the portal tracts was also observed. This could be explained by accumulation of bile. This induces proliferation of the duct epithelial cells, looping and reduplication of ducts, termed bile duct proliferation [1]. Ito stellate cells are fat-storing cells of the liver. They were identified by immunoreactivity to glial fibrillary acidic protein (GFAP) [26]. Histologically, they are characterized by prominent intracellular lipid droplets and by cytoplasmic filamentous material, which form the basis of their immunoreactivity to GFAP. Quantitative estimates indicate that Ito stellate cells constitute about $10-12 \%$ of hepatocytes in rat liver [27,28]. Activation of hepatic stellate cells leads to fibrosis. A crosslink between liver sinusoidal endothelial cells (LSECs) and hepatic stellate cells was illustrated [29]. Healthy LSECs prevent the activation of hepatic stellate cells and inactivate activated hepatic stellate cells [30]. LSECs develop an altered phenotype preceding hepatic fibrosis, which is called capillarization. Capillarized LSECs lose their ability to prevent hepatic stellate cell activation and inactivate activated hepatic stellate cells. In a rat model of hepatic fibrosis, reversal of capillarization of LSECs inactivates activated hepatic stellate cells and accelerates reversal of fibrosis, whereas reversal of capillarization during an ongoing insult prevents progression of cirrhosis [31]. The previous suggestions were confirmed by GFAP immunohistochemical study as there was an increase in the number of Ito cells in the anthracene treated group. In the present work, the mean $\%$ area of caspase- 3 positive reaction was significantly increased compared with the control group. This could be explained by elevated concentrations of toxic bile acids (TBAs) within hepatocytes. TBAs can activate the endoplasmic stress pathway with generation of reactive oxygen species. TBAs also sensitize hepatocytes to certain receptors. The activated receptor complexes cause caspase apoptotic cascade and induce apoptosis [32]. The protected group preserved nearly normal lung structure. However, some amount of inflammatory cell infiltration and a few congested blood vessels were still present.

The protected group also showed a nearly normal liver architecture. Some central veins showed mild congestion and some hepatocytes still showed dark disintegrated nuclei. Immunohistochemical expressions were significantly down-regulated compared with anthracene treated rats. O. gratissimum possesses diverse pharmacological properties that include antioxidant, antibiotic, antidiabetic, antiatherogenic, immunomodulatory [33], anti-inflammatory, analgesic, antiulcer, and chemo-preventive and antipyretic properties [34]. Few studies have also demonstrated the potential of O. gratissimum as an anti-tumor agent, inhibiting the proliferation of human oral squamous cell carcinoma and mouse leukemia cells (P388) in vitro [35]. Other studies have shown that its ethanolic extracts exhibited a cytotoxic effect against A549 lung cancer cells, cleaved the pro-apoptotic molecule, poly(ADP-ribose) polymerase (PARP), promoted the release of cytochrome C, increased the activity of caspases 3 and 9 and the ratio of Bax/Bcl-2 [36]. Overall, these studies suggest that extract from the leaves of the plant inhibit cell cycle progression and prevent metastasis [37]. 


\section{Conclusion}

Anthracene has toxic effect on the lung and liver of albino rats that can be Ameliorated by Ocimum gratissimum extract.

\section{Author's contribution}

Both authors have contributed equally to this work.

\section{References}

1. Faust RA (1991) Oak Ridge National Laboratory, Chemical Hazard Evaluation Group. Toxicity Summary for Anthracene, Oak Ridge, Tennessee, USA.

2. Wang Q, Xue Y (2015) Characterization of Solid Tumors Induced by Polycyclic Aromatic Hydrocarbons in Mice. Med Sci Monit Basic Res 21: 81-5.

3. Ramesh A, Kumar A, Aramandla MP, Nyanda AM (2015) Polycyclic Aromatic Hydrocarbon Residues in Serum Samples of Autopsied Individuals from Tennessee. Int J Environ Res Public Health 12: 322-34.

4. Unwin J, Cocker J, Scobbie E, Chambers H (2006) An Assessment of Occupational Exposure to Polycyclic Aromatic Hydrocarbons in the UK. Ann Occup Hyg 50: 395-403.

5. Supinska k, Misiewicz I, Guttman TK (2004) Polycyclic aromatic hydrocarbons: physicochemical properties, environmental appearance and impact on living organisms. Acta Pol Pharm 61: 233-40.

6. Ijeh II, Omodamiro OD, Nwanna IJ (2005) Antimicrobial effects of aqueous and ethanolic fractions of two spices, Ocimum gratissimum and Xylopia aethiopica. Afr J Biotechnol 4: 953-6.

7. Freire CM, Marques MO, Costa M (2006) Effects of seasonal variation on the central nervous system activity of Ocimum gratissimum L. essential oil. J Ethnopharmacol 105: 161-6.

8. Akinmoladun AC, Ibukun EO, Afor E, Obuotor EM, Farombi EO (2007) Phytochemical constituent and antioxidant activity of extract from the leaves of Ocimum gratissimum. Sci Res Essay 2: 163-6.

9. Asuquo O, Edet A, Mesembe O, Atanghwo J (2010) Ethanolic Extracts Of Vernonia Amygdalina And Ocimum Gratissimum Enhance Testicular Improvement In Diabetic Wistar Rats. Internet J Altern Med 8: 2.

10. Agency for Toxic Substances and Disease Registry (1995) Public Health Statement, Polycyclic Aromatic Hydrocarbons. Atlanta, GA: U.S. Department of Health and Human Services.

11. Lange M, Szabo C, Traber DL, Horvath E, Hamahata A, et al. (2012) Time profile of oxidative stress and neutrophil activation in ovine acute lung injury and sepsis. Shock 37: 468-72.

12. Demirbilek S, Sizanli E, Karadag N, Karaman A, Bayraktar N, et al. (2006) The effects of methylene blue on lung injury in septic rats. Eur Surg Res 38: $35-41$.

13. Karpurapu M, Wang X, Deng J, Park H, Xiao L, et al. (2011) Functional PU.1 in macrophages has a pivotal role in NF-B activation and neutrophilic lung inflammation during endotoxemia. Blood 118: 5255-66.

14. Rosseau S, Hammerl P, Maus U, Walmrath HD, Schütte H, et al. (2000) Phenotypic characterization of alveolar monocyte recruitment in acute respiratory distress syndrome. Am J Physiol Lung Cell Mol Physiol 279: L25-35.

15. Donnelly SC, Haslett C, Reid PT, Grant IS, Wallace WA, et al. (1997) Regulatory role for macrophage migration inhibitory factor in acute respiratory distress syndrome. Nat Med 3: 320-3.

16. Bernhagen J, Calandra T, Mitchell RA, Martin SB, Tracey KJ, et al. (1993) MIF is a pituitary-derived cytokine that potentiates lethal endotoxaemia. Nature 365: 756-9.

17. Marmugi A, Ducheix S, Lasserre F, Polizzi A, Paris A, et al. (2012) Low doses of bisphenol A induce gene expression related to lipid synthesis and trigger triglyceride accumulation in adult mouse liver. Hepatology 55: 395-407.

18. Zidan, Ahmad R (2011) Effect of long-term administration of amiodarone on rat lung and the possible protective role of vitamin E: a histological and immunohistochemical study. Egypt J Histol 34: 117-28.

19. Matthay MA, Ware LB, Zimmerman GA (2012) The acute respiratory distress syndrome. J Clin Invest 122: 2731-40.

20. Viaro F, Nobre F, Evora PR (2000) Expression of nitric oxide synthases in the pathophysiology of cardiovascular diseases. J Arq Bras Cardiol 74: 380-93.

21. Takimoto E, David A, Kass A (2007) Role of oxidative stress techniques (6th Edn) New York, London: Churchill Livingstone, USA.

22. Lee WM, Senior JR (2005) Recognizing drug-induced liver injury: current problems, possible solutions. Toxicol Pathol 33: 155-64.

23. Andrade RJ, Lucena MI, Fernández MC, Pelaez G, Pachkoria K, et al. (2005) Drug-induced liver injury: an analysis of 461 incidences submitted to the Spanish registry over a 10-year period. Gastroenterology 129: 512-21.

24. Celik I, Turker M, Tuluce Y (2007) Abcisic acid and gibberellic acid cause increased lipid peroxidationand fluctuated antioxidant defense systems of various tissues in rats. J Hazard Mater 148: 623-9.

25. Rubin R, Strayer DS (2012) Rubin's Pathology: Clinicopathologic Foundations of Medicine (6th Edn) Philadelphia: Lippincott Williams\&Wilkins, USA.

26. Neubauer K, Knittel T, Aurisch S, Fellmer P, Ramadori G (1996) Glial fibrillary acidic protein - a cell type specific marker for Ito cells in vivo and in vitro. J Hepatol 24: 719-30.

27. De Bleser P, Geerts A, Wisse E (1991) Role of fat-storing cells in hepatic fibrogenesis. Retinoids as possible therapeutic agents. Alcohol Alcohol Suppl 1: 345-50.

28. Baratta JL, Ngo A, Lopez B, Kasabwalla N, Longmuir KJ, et al. (2009) Cellular organization of normal mouse liver: a histological, quantitative immunocytochemical, and fine structural analysis. Histochem Cell Biol 131: 713-26.

29. DeLeve LD, Wang X, Hu L, McCuskey MK, McCuskey RS (2004) Rat liver sinusoidal endothelial cell phenotype is maintained by paracrine and autocrine regulation. Am J Physiol Gastrointest Liver Physiol 287: G757-63.

30. Deleve LD, Wang X, Guo Y (2008) Sinusoidal endothelial cells prevent rat stellate cell activation and promote reversion to quiescence. Hepatology 48: 920-30.

31. Xie G, Wang X, Wang L, Wang L, Atkinson RD, et al. (2012) Role of differentiation of liver sinusoidal endothelial cells in progression and regression of hepatic fibrosis in rats. Gastroenterology 142: 918-27.

32. Wang K (2014) Molecular mechanisms of hepatic apoptosis. Cell Death Dis 5: e996. 
33. Manosroi J, Dhumtanom P, Manosroi A (2006) Anti-proliferative activity of essential oil extracted from Thai medicinal plants on KB and P388 cell lines. Cancer Lett 235: 114-20.

34. Iweala EEJ, Obidoa O (2010) Studies on some biochemical and histological changes associated with long term consumption of leaves of Ocimum gratissimum L. in male rats. Am J Food Technol 5: 376-84.

35. Hakkim FL, Arivazhagan G, Boopathy R (2008) Antioxidant property of selected Ocimum species and their secondary metabolite content. J Med Plants Res 2: 250-7.

36. Agnaniet H, Anguillet JJ, Bessière JM, Menut C (2005) Aromatic plants of tropical central Africa. Part XLVII. Chemical and biological investigation of essential oils of Ocimum species from Gabon. J Essent Oil Res 17: 466-70.

37. Leal PF, Chaves FCM, Ming LC, Petenate AJ, Meireles MAA (2006) Global yields, chemical compositions and antioxidant activities of clove basil (Ocimum gratissimum L.) extracts obtained by supercritical fluid extraction. J Food Proc Eng 29: 547-59.

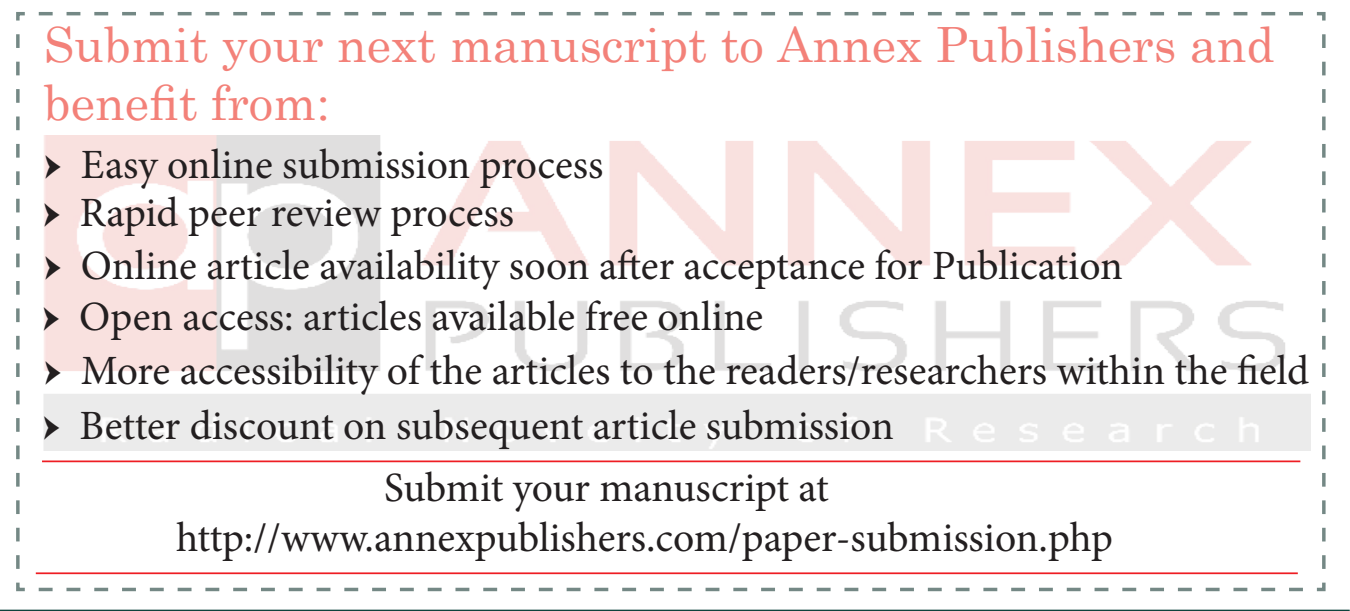

